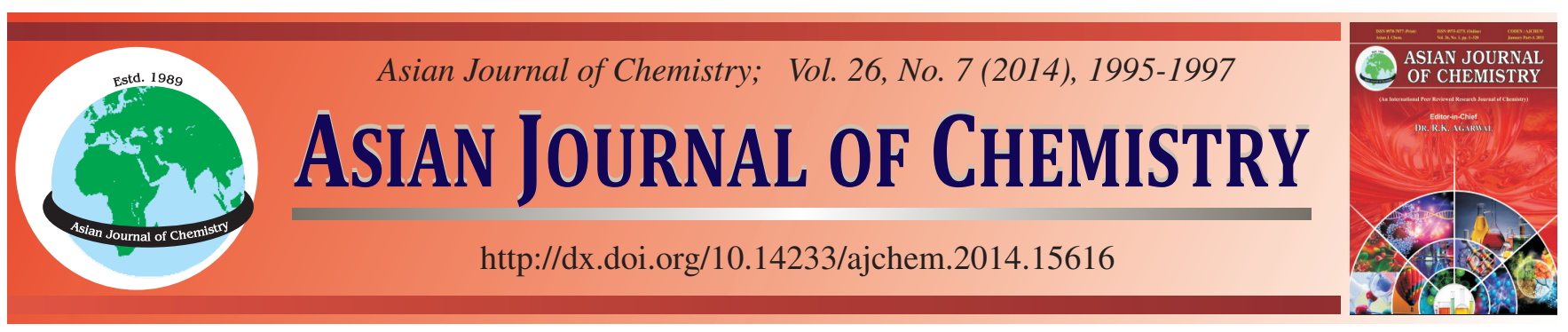

\title{
Synthesis of Glyoxalic Acid Using Methyl Dichloroacetate by Microwave Method
}

\author{
Qian Niu, Xiong Luo, Shou-Gao Li, Ying Meng and Fu-Xiang Li*
}

Research Institute of Special Chemicals, Taiyuan University of Technology, Taiyuan 030024, Shanxi Province, P.R. China

*Corresponding author: Fax: +86 351 6111178; Tel: +86 351 6010550-3; E-mail: L63f64x@163.com; rencizhe@126.com

Microwave irradiation was used to synthesize glyoxalic acid from methyl dichloroacetate. The effects of the irradiation time, reaction temperature, reactant ratio and different alkali on the yield of glyoxalic acid were studied and also compared with those effects under conventional heating. The yield of glyoxalic acid can reach $84.6 \%$ within $6 \mathrm{~h}$ under the microwave irradiation, which is $12.2 \%$ higher than that under conventional heating within $12 \mathrm{~h}$. The optimum reaction time is $7.5 \mathrm{~h}$ and the optimum reaction temperature is $75^{\circ} \mathrm{C}$ under the microwave irradiation. The results indicated that microwave irradiation was superior to the conventional heating obviously.

Keywords: Microwave irradiation, Methyl dichloroacetate, Synthesis, Glyoxalic acid.

\section{INTRODUCTION}

Glyoxalic acid, the most simple keto acid, has properties of both acids and aldehyde, which could be found in some animal's body fluids and unripened fruits. As an important organic synthesis intermediate, glyoxalic acid can be widely applied in fine chemicals synthesis, such as varnish, medicine, dyestuff, spicery, plastics additives and industrial chemicals. It can also be used in the production of oral penicillin, vanillin and allantoin, $e t c^{1}$.

Several techniques have been reported to produce glyoxalic acid including, oxidation of glyoxal ${ }^{2,3}$, ozonation of maleic acid $^{4}$, hydrolysis oxidation of dichloroacetic acid ${ }^{5}$ and oxalic acid electrochemical reduction ${ }^{6,7}$. But all these methods have many disadvantages such as huge facilities, large investments, complex mechanical works and potential environmental pollutions, high costs for operating and maintaining. Thus, the methods mentioned above are not satisfying in practical application, it is urgent to seek a reasonable and economic method.

Methyl dichloroacetate is a by-product when producing methyl chloroacetate by using methanol esterify mother liquor of chloroacetic acid (contains 30-35 \% dichloroacetic acid). The synthesis process of the glyoxalic acid using the methyl dichloroacetate as the raw material has the characteristics of simple process, low costs and good product quality. At the same time it also takes advantage of the mother liquor of chloroacetic acid and reduces emissions to the environment.

As a new heating technology, the microwave extraordinarily improves the efficiency and yields and shortens reaction time in organic synthesis. The microwave irradiation method has been applied to many kinds of reactions in organic synthesis and is becoming one of the hot point for green chemical reaction lately.

The yield of glyoxalic acid from the hydrolysis reaction of methyl dichloroacetate under conventional heating method ${ }^{8}$ is only $70 \%$. We have reported a novel microwave heating technique as an alternative to the conventional heating in synthesis of glyoxalic acid. This paper aims to explore the speed and degree of reaction under the condition of microwave and to find the optimal reaction conditions for the synthesis of glyoxalic acid, to provide application foundation and technical support for comprehensive utilization of methyl dichloro acetate. The reaction equations are described as follows:

$$
\begin{aligned}
\mathrm{Cl}_{2} \mathrm{CHCOOCH}_{3}+ & \mathrm{H}_{3} \mathrm{COH} \underset{\mathrm{NaOH}}{\longrightarrow} \\
& \left(\mathrm{H}_{3} \mathrm{CO}\right)_{2} \mathrm{CHCOONa}+\mathrm{NaCl} \\
\left(\mathrm{H}_{3} \mathrm{CO}\right)_{2} \mathrm{CHCOONa}+ & \mathrm{H}_{2} \mathrm{SO}_{4} \rightarrow \mathrm{OCHCOOH}+\mathrm{Na}_{2} \mathrm{SO}_{4}
\end{aligned}
$$

\section{EXPERIMENTAL}

Ethyl dichloroacetate (Industry grade, purity $99.9 \%$ ), w $($ sulfuric acid $)=98 \%$, sodium hydroxide $(\mathrm{AR}, 96.0 \%)$, potassium hydroxide (AR, 85.0 \%), sodium carbonate (AR, 99.8\%), sodium bicarbonate (AR, $99.5 \%$ ), sodium acetate (AR, $99.0 \%)$, potassium carbonate (AR, 99.0\%) and methanol (AR, $99.5 \%$ ). Microwave chemistry reactor (Gongyi City Yuhua Instrument CO., LTD) with microwave frequency 2450 $\mathrm{MHz}$, power 80-800 W.

Synthesis of glyoxalic acid: In a $100 \mathrm{~mL}$, three-necked, round-bottomed flask a certain quantity of methanol should 
be added, then a moderate amount of sodium hydroxide to join in methanol, fully stirring and dissolving. After $1 \mathrm{~h}$, a quantity of methyl dichloroacetate was added to methanol under different conditions and the solid was filtered out after a period of heat-preservation stirring. The cake was washed three times with a moderate amount of methanol, merging of filtrates. An appropriate amount of sulfuric acid (50\%) was added into the filtered liquor to adjust the $\mathrm{pH}$ value to about 2-3 after the separation of salts, stirring $1.5 \mathrm{~h}$ keeping the temperature at $30{ }^{\circ} \mathrm{C}$ or below, then filter out solid. The cake was washed three times with a moderate amount of methanol, merging of filtrates, obtaining glyoxalic acid solution.

Determination of glyoxalic acid': About $1 \mathrm{~g}$ solution of glyoxalic acid was added into $25 \mathrm{~mL}$ distilled water and $10 \mathrm{~mL}$ sulfuric acid (1:5), heated to $60-80{ }^{\circ} \mathrm{C}$. Titration endpoints can be identified by the fact that when using $0.02 \mathrm{~mol}$ $\mathrm{L}^{-1}$ standard $\mathrm{KMnO}_{4}$ solution titrant to titrate the solution to red and which do not fade about $30 \mathrm{~s}$. The concentration of glyoxalic acid can be calculated according to the following equation:

$$
\text { Glyoxalic acid } \%=\frac{\mathrm{N} \times \mathrm{V} \times 74}{\mathrm{G} \times 1000} \times 100
$$

where, $\mathrm{N}$ represents molar concentration of standard $\mathrm{KMnO}_{4}$ solution, $\mathrm{mol} \mathrm{L}^{-1}$. V represents consumption volume of $\mathrm{KMnO}_{4}$ solution, $\mathrm{mL}$. G represents sample weight, g. The molecular weight of glyoxalic acid is 74 .

\section{RESULTS AND DISCUSSION}

Effect of reaction temperature on the yield of glyoxalic acid: The yield of glyoxalic acid was measured at different temperatures with same power of microwave radiation for $6 \mathrm{~h}$, in the mixed solvent of $40 \mathrm{~mL}$ methanol, $7.5 \mathrm{~g}$ sodium hydroxide and $5.2 \mathrm{~mL}(0.5 \mathrm{~mol})$ methyl dichloroacetate (Fig. 1).

Results in Fig. 1 are shown that the yield increases with the rise of temperature, but the extent of the improvement of yields will decrease when the temperature is above $65{ }^{\circ} \mathrm{C}$. Due to microwave treatment, with solution temperature rising gradually, molecules vibrate faster and friction increases, which are good for the production of the glyoxalic acid. If the tempe-

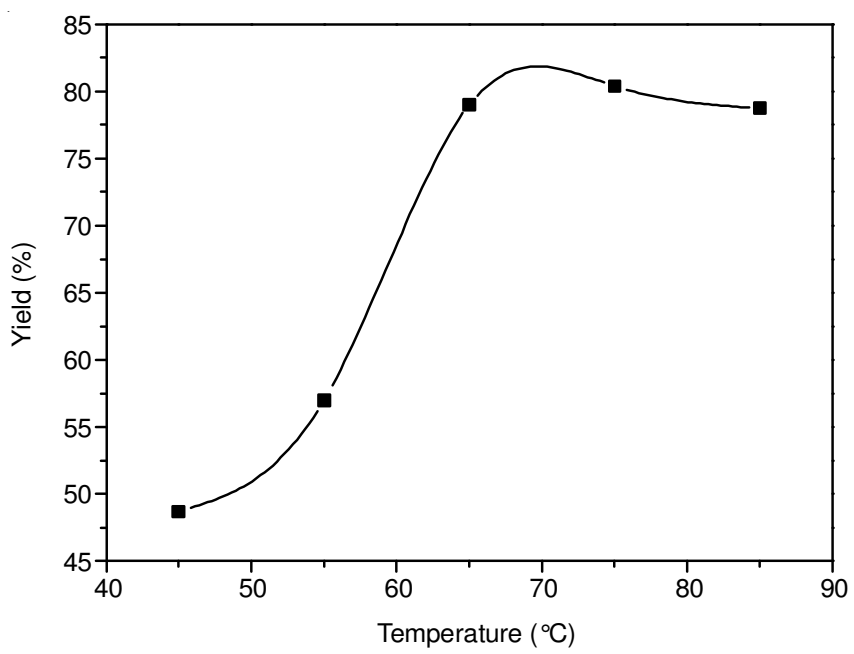

Fig. 1. Effect of different temperature on the glyoxalic acid yield rature continues to raising, heat effect may have some damage on the active ingredients of the glyoxalic acid, so $75^{\circ} \mathrm{C}$ is a suitable temperature.

Effect of reaction time on the yield of glyoxalic acid: In a mixed solvent of $40 \mathrm{~mL}$ methanol, $7.5 \mathrm{~g}$ sodium hydroxide and $5.2 \mathrm{~mL}(0.5 \mathrm{~mol})$ methyl dichloroacetate, the reaction would be efficiently carried out at $75^{\circ} \mathrm{C}$, at various time in the same power of microwave radiation for $6 \mathrm{~h}$. And then determinate the yield of glyoxalic acid. Compared those with conventional heating, the results are shown in Fig. 2.

The yield of glyoxalic acid rises with reaction time increasing. The reaction time is longer, the faster the reactions rate will be. But the improvement is low when the reaction time is above $6 \mathrm{~h}$ and the basic yield maintains around $80 \%$. This may be that as the extension of reaction time, the local temperature will be too high and might bring in much byproducts, as well as reaction material methanol evaporation, glyoxalic acid decomposition and carbonization and thus cause the production rate to drop, so $6 \mathrm{~h}$ is a suitable reaction time. It only took $4 \mathrm{~h}$ for microwave irradiation but $12 \mathrm{~h}$ for conventional heating when yield of glyoxalic acid reaches $70 \%$. It is clear that the reaction rate under microwave heating is 3 times higher than that of conventional heating.

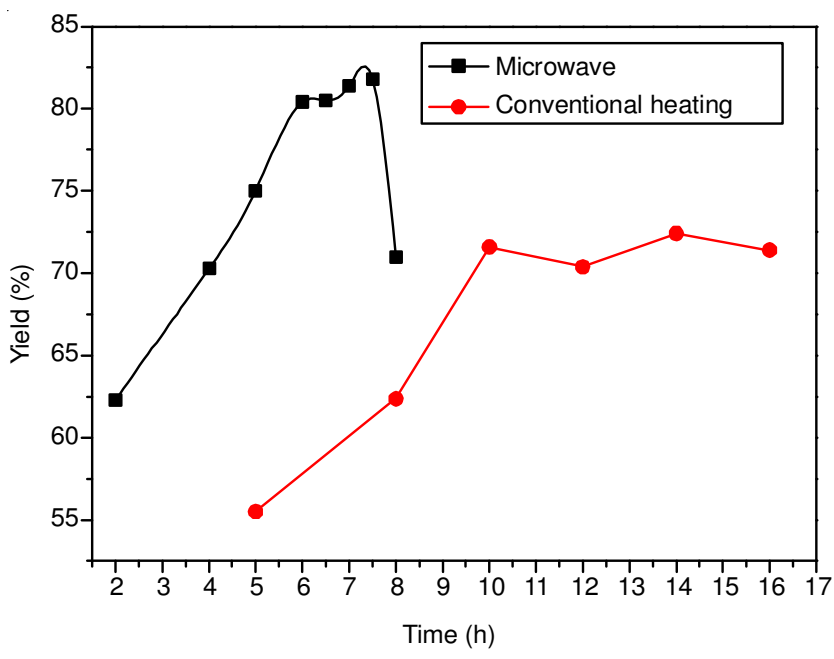

Fig. 2. Effect of different reaction time on the glyoxalic acid yield

Effect of different alkali on the yield of glyoxalic acid: The methyl dichloroacetate and different kinds of alkali molar ratio 3.75:1 were respectively added to $40 \mathrm{~mL}$ of methanol, in the same power of microwave with methyl dichloro-acetate radiation $6 \mathrm{~h}$, determination of glyoxalic acid (Table-1).

Results showed that the different alkali has a relatively great different influence on the glyoxalic acid production rates.

\begin{tabular}{lcccc}
\multicolumn{5}{c}{ TABLE-1 } \\
\multicolumn{5}{c}{$\begin{array}{c}\text { EFFECT OF DIFFERENT ALKALI ON } \\
\text { THE YIELD OF GLYOXALIC ACID }\end{array}$} \\
\hline \multicolumn{1}{c}{ Alkali } & $\begin{array}{c}\text { Quality } \\
(\mathrm{g})\end{array}$ & $\begin{array}{c}\text { Temperature } \\
\left({ }^{\circ} \mathrm{C}\right)\end{array}$ & $\begin{array}{c}\text { Methanol } \\
(\mathrm{mL})\end{array}$ & $\begin{array}{c}\text { Yield } \\
(\%)\end{array}$ \\
\hline $\mathrm{CH}_{3} \mathrm{COONa}$ & 15.4 & 65 & 40 & 3.68 \\
$\mathrm{Na}_{2} \mathrm{CO}_{3}$ & 19.9 & 65 & 40 & 5.20 \\
$\mathrm{~K}_{2} \mathrm{CO}_{3}$ & 25.9 & 65 & 60 & 5.70 \\
$\mathrm{NaHCO}_{3}$ & 15.8 & 65 & 40 & 7.60 \\
$\mathrm{KOH}$ & 10.5 & 75 & 40 & 77.00 \\
$\mathrm{NaOH}$ & 7.50 & 75 & 40 & 80.40 \\
\hline
\end{tabular}


It is seen that $\mathrm{NaOH}$ as a reactant is a suitable alkali with high yield.

Effect of $\mathrm{NaOH} / \mathrm{C}_{3} \mathrm{H}_{4} \mathrm{Cl}_{2} \mathrm{O}_{2}$ molar ratio on the yield of glyoxalic acid: $5.2 \mathrm{~mL}(0.5 \mathrm{~mol})$ methyl dichloroacetate, in the same power of microwave radiation $6 \mathrm{~h}$, the reaction would be efficiently carried out at $75{ }^{\circ} \mathrm{C}$, effects of the $\mathrm{NaOH} /$ $\mathrm{C}_{3} \mathrm{H}_{4} \mathrm{Cl}_{2} \mathrm{O}_{2}$ molar ratio on the yield of glyoxalic acid are shown in Table-2 and Fig. 3.

\begin{tabular}{|c|c|c|c|}
\hline \multicolumn{4}{|c|}{$\begin{array}{c}\text { TABLE-2 } \\
\text { EFFECTS OF NaOH/ } \mathrm{C}_{3} \mathrm{H}_{4} \mathrm{O}_{2} \mathrm{Cl}_{2} \text { MOLAR RATIO } \\
\text { ON THE YIELD OF GLYOXALIC ACID }\end{array}$} \\
\hline & $\begin{array}{c}\mathrm{NaOH} / \mathrm{C}_{3} \mathrm{H}_{4} \mathrm{Cl}_{2} \mathrm{O}_{2} \\
\text { molar ratio }\end{array}$ & Methanol (mL) & Yield (\%) \\
\hline 1 & $3.25: 1$ & 34.5 & 76.4 \\
\hline 2 & $3.50: 1$ & 36.5 & 78.0 \\
\hline 3 & $3.75: 1$ & 40.0 & 80.4 \\
\hline 4 & $4.00: 1$ & 41.5 & 82.2 \\
\hline 5 & $4.25: 1$ & 45.0 & 84.6 \\
\hline 6 & $4.50: 1$ & 48.0 & 79.9 \\
\hline
\end{tabular}

In the synthesis of glyoxalic acid process, the synthesis of dimethoxy acetate sodium are the key steps in the reaction ${ }^{8}$. The results are shown in Table- 2 and Fig. 3, the $\mathrm{NaOH} /$ $\mathrm{C}_{3} \mathrm{H}_{4} \mathrm{O}_{2} \mathrm{Cl}_{2}$ molar ratio has a relatively great influence on the glyoxalic acid production rates. With the increasing of the

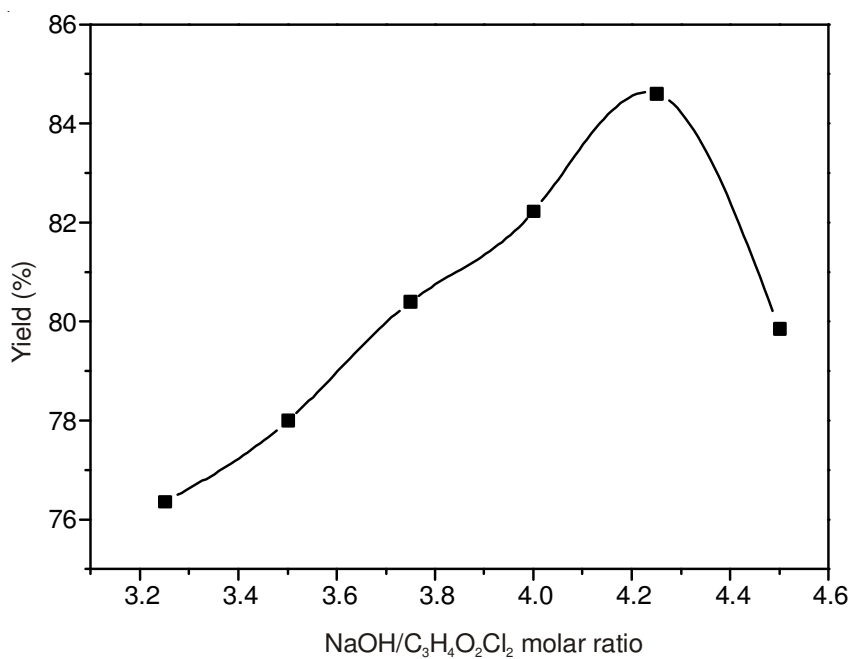

Fig. 3. Effect of $\mathrm{NaOH} / \mathrm{C}_{3} \mathrm{H}_{4} \mathrm{O}_{2} \mathrm{Cl}_{2}$ molar ratio on the yield of glyoxalic acid
$\mathrm{NaOH} / \mathrm{C}_{3} \mathrm{H}_{4} \mathrm{O}_{2} \mathrm{Cl}_{2}$ molar ratio, the yields are improving, but the improvement are low when the $\mathrm{NaOH} / \mathrm{C}_{3} \mathrm{H}_{4} \mathrm{O}_{2} \mathrm{Cl}_{2}$ molar ratio is above 4.25:1, at the same time consumption of sulfuric acid increases. The increase of dosage of sodium hydroxide could increase the yield of production in certain scope, but the excess increasing of them might bring in much by-products and would increase the loss of glyoxalic acid in post-processing, so 4.00 molar ratio of $\mathrm{NaOH} / \mathrm{C}_{3} \mathrm{H}_{4} \mathrm{O}_{2} \mathrm{Cl}_{2}$ is suitable.

\section{Conclusion}

Microwave irradiation was used to synthesize glyoxalic acid from methyl dichloroacetate. Under the same reagent application, in comparison with the conventional heating, the microwave irradiation greatly reduced the synthesis time. It only took $4 \mathrm{~h}$ for microwave irradiation but $12 \mathrm{~h}$ for conventional heating if the yield of glyoxalic acid reaches $70 \%$. It is clearly that the reaction rate under microwave heating was 3 times higher than that of conventional heating.

Under the optimum microwave irradiation condition, the yield of glyoxalic acid was $84 \%$, which is higher than the yield $(72 \%)$ obtained under traditional heating method. The reason may be that both quantity and energy activated molecules in microwave field is higher than that in thermal environment and the distribution is more uniform at the same temperature.

In conclusion, the microwave irradiation can greatly reduce the synthesis time, increase the production yield and meet the development requirements of green chemistry.

\section{REFERENCES}

1. H.Y. Gao, Shanghai Chem. Ind., 27, 51 (2002).

2. A. Schouteen and J.M. Alarcon, Process for Continuous Industrial Preparation of Anacqeous Solution of Glyoxalic Acid, EP428429 (1991).

3. I. Capriov, Oxid. Commun., 8, 263 (1985).

4. D.R. Cai. Hebei Chem. Eng. Ind., 4, 5 (1994).

5. H.J. Bao and S.T. Han. Mother Liquor of Chloroacetic Acid Synthesizing Glyoxalic Acid, CNl 070184A (1993).

6. Y. Hou, X.H. He and T.R. Tong, Chem. World, 33, 37 (1992).

7. D.J. Pickett and K.S. Yap, J. Appl. Electrochem., 4, 17 (1974).

8. H.J. Zhou, D.C. Fu and X.Y. Qin, J. Hebei Normal Univ., 27, 490 (2004).

9. X.Q. Liu, J.Y. Liu and Y.F. Zhang, Chem. Bioeng., 6, 42 (2004). 